\title{
Characterization of Peroxidase in Tartary Buckwheat Seed
}

Tatsuro SuZuki ${ }^{1 *}$, Dong-Hoon $\mathrm{SHIN}^{2}$, Sun-Hee $\mathrm{WoO}^{2}$, Yuji MukAsa ${ }^{3}$, Toshikazu Morishita ${ }^{1}$, Takahiro Noda ${ }^{1}$, Shigenobu Takigawa ${ }^{1}$, Naoto Hashimoto ${ }^{4}$, Hiroaki Yamauchi ${ }^{3}$ and Chie MatsuURa-Endo ${ }^{1}$

\author{
${ }^{I}$ NARO Hokkaido Agricultural Research Center, Shinsei, Memuro, Kasai-Gun, Hokkaido 082-0081, Japan \\ ${ }^{2}$ Lab. of Plant Breeding \& Plant Functional Proteomics, Dept of Crop Science, College of Agricultural, Life \& Environmental Sciences \\ Chungbuk National University, 410, Seongbong-ro, Gaeshin-dong, Cheongju City, 361-763 Chungbuk, Korea \\ ${ }^{3}$ NARO Hokkaido Agricultural Research Center, 1 Hitsujigaoka, Toyohira, Sapporo, Hokkaido 062-8555, Japan \\ ${ }^{4}$ NARO Kyushu Okinawa Agricultural Research Center, 2421 Suya, Koshi, Kumamoto 861-1192, Japan
}

Received January 22, 2011; Accepted April 9, 2012

Tartary buckwheat is targeted as a healthy food because its food contains large amounts of polyphenols such as rutin and quercetin, especially. Quercetin is a substrate for POX activity, which sometimes plays important roles for quality changes in foods. Therefore, to obtain a basic understanding of the roles of Tartary buckwheat POX, we purified and characterized POX in Tartary buckwheat seeds. POX was purified (76.7 fold, final yield 4.77\%). Tartary buckwheat seeds bore a single major POX (MW 46.8 kDa). Kinetic studies revealed that POX had lower $K_{\mathrm{m}}$ values for quercetin $(0.32 \mathrm{mM})$ and $o$-dianisidine $(0.316$ $\mathrm{mM})$ than for ABTS $(1.86 \mathrm{mM})$ and guaiacol $(0.958 \mathrm{mM})$. POX showed greater activity under acidic pH conditions. Optimum pH of POX was the same pH as Tartary buckwheat dough. In addition, optimum temperature was around $20^{\circ} \mathrm{C}$, corresponding to the temperature where dough is usually handled. Therefore, POX in Tartary buckwheat may play an important role in quality changes in food.

Keywords: tartary buckwheat, peroxidase, characterization, purification, quality

\section{Introduction}

Plant peroxidase (EC 1.11.1.7; POX), widely distributed in higher plants (Van et al., 1982), is involved in a variety of physiological functions: cell elongation (Ahmed et al., 1995), defense mechanisms (Bradley et al., 1992; Kolattukudy, Mohan et al., 1992) and lignification (Blee et al., 2003). POX also plays an important role in food quality, particularly with regard to deterioration of color and flavor (Ashie et al., 1996). Primary contributors to undesirable 'beany' and 'green' flavors in soybean (Glycine max Merr.), aldehydes and ketones are mainly generated through lipid peroxidation. Their presence has been linked to the activity of enzymes such as lipoxygenase (EC 1,13,11,12) and POX (Matoba et al., 1975; Matoba et al., 1985; Anli et al., 2004). POX also plays an important role in the deterioration of flavor and taste in butterbur [Petasites japonicas Maxim.] (Ibaraki et al., 1988; Ibaraki et al., 1989).

Common buckwheat (Fagopyrum esculentum Moench) is

*To whom correspondence should be addressed. E-mail: tsuzu@affrc.go.jp considered a healthy food. In Japan, buckwheat flour is used mainly for making noodles, and its flavor and color are important factors in its quality. Buckwheat flour's rapid deterioration (Muramatsu et al., 1986) has been linked to enzymatic activities (Kondo et al., 1982; Ohinata et al., 1997; Suzuki et al., 2004; Suzuki et al., 2005). Partially characterizing POX from F. esculentum seeds, Kondo (1982) suggested that POX influenced the oxidation of flavonoids in such seeds. In purifying and characterizing POX activity extracted from $F$. esculentum seeds, Suzuki et al. (Suzuk et al., 2006) showed this activity to be associated with at least two isozymes, both capable of catalysis at temperatures approaching $0^{\circ} \mathrm{C}$. They further demonstrated these enzymes to have a lower $K_{\mathrm{m}}$ for quercetin than for other phenolic compounds such as guaiacol. As with lipase, POX activity has been significantly correlated with lipid deterioration in $F$. esculentum flour during storage (Suzuki et al., 2004; Suzuki et al., 2006).

Tartary buckwheat (F. tataricum Gaertner) is also known to be a useful food because it contains about 100 times more rutin in its seed than common buckwheat (Suzuki et al., 2002; Suzuki et al., 2004). Tartary buckwheat seeds also 
contains large amount of rutinosidase activity; therefore rutin in Tartary buckwheat flour is easily hydrolyzed to functional flavonoid quercetin (Yasuda et al., 1994; Suzuki et al., 2002). However, its flour deteriorates easily, and, as with F. esculentum flour, POX may have an important role in this process. Therefore, to obtain a basic understanding of the roles of $F$. tataricum POX activity in seeds, we purified and characterized POX from $F$. tataricum seeds.

\section{Materials and Methods}

Plant materials $\quad F$. tataricum and $F$. esculentum genetic resources/varieties were grown in an experimental field at the National Agricultural Research Center for the Hokkaido Region, Memuro, Hokkaido, Japan (latitude: 42 ${ }^{\circ} 3^{\prime}$, longitude: $\left.143^{\circ} 03^{\prime}\right)$. F. tataricum and F. esculentum seeds were sown early in June and harvested in late August in 2008. Harvested seeds were dried, threshed and stored at $4^{\circ} \mathrm{C}$ until used for experiments.

Assay of in vitro POX activity POX activities were assayed by modification of the procedure described by Suzuki (Suzuki, et al., 2006). POX activities were determined at $22^{\circ} \mathrm{C}$ by measuring the initial rate of decrease in absorbance at $370 \mathrm{~nm}$ (quercetin) or the increase in absorbance at $430 \mathrm{~nm}$ (o-dianisidine), $415 \mathrm{~nm}$ (ABTS; 2,2'-azino-bis-(3ethylthiazoline-6-sulfonate), and $490 \mathrm{~nm}$ (guaiacol). The assay mixture contained $200 \mathrm{mM}$ buffer (at the optimal $\mathrm{pH}$ for POX activity for each substrate), $3 \mathrm{mM} \mathrm{H}_{2} \mathrm{O}_{2}$, substrate (2 $\mathrm{mM}$ quercetin, $12 \mathrm{mM} o$-dianisidine, $10 \mathrm{mM} \mathrm{ABTS}$, or 15 $\mathrm{mM}$ guaiacol) and $10 \mu \mathrm{L}$ of enzyme solution in a total volume of $200 \mu \mathrm{L}$.

Purification of F. tataricum $P O X \quad$ Following the removal of panicles, F. tataricum seeds were milled. Tartary buckwheat flour (100 g fresh weight) was homogenized with $1000 \mathrm{~mL}$ of buffer A (50 mM acetate-LiOH buffer, $\mathrm{pH}$ 5.5) for about $1 \mathrm{~h}$. A crude enzyme solution was obtained by centrifugation and then precipitated by $0-80 \%$ saturation with solid $\left(\mathrm{NH}_{4}\right)_{2} \mathrm{SO}_{4}$. The precipitate was dissolved in buffer $\mathrm{A}$ and dialyzed overnight against buffer A. The dialyzed enzyme solution was applied to a CM-Sepharose column (24 $\times 115 \mathrm{~mm}$, GE Healthcare Japan, Tokyo, Japan) equilibrated with buffer A. The POX was eluted using a linear $600 \mathrm{ml}$ gradient of 50 to $400 \mathrm{mM} \mathrm{LiCl}$ in buffer A. Active fractions were collected and loaded onto a Sephacryl S-200 column (24 $\times 66 \mathrm{~mm}$, GE Healthcare Japan, Tokyo, Japan) equilibrated with buffer A. Active fractions were collected and stored at $-30^{\circ} \mathrm{C}$. In each purification step, POX activity was measured using guaiacol as substrate. All of the above steps were carried out at $4^{\circ} \mathrm{C}$.

Determination of optimal $\mathrm{pH}, \mathrm{pH}$ stability, optimal temperature, thermal stability and $K_{m}$ value of F. tataricum POX
To investigate the enzyme's optimal $\mathrm{pH}, F$. tataricum $\mathrm{POX}$ activity at $22^{\circ} \mathrm{C}$, with quercetin, ABTS and guaiacol respectively as substrates, was determined at different pHs: 2.0 (200 mM glycine - $\mathrm{HCl}$ buffer), 3.0 to 4.0 (200 mM citrate LiOH buffer), 5.0 to 6.0 (200 mM acetate - LiOH buffer), 7.0 (200 mM imidazole - LiOH buffer), 8.0 (200 mM tris - $\mathrm{HCl}$ buffer), or 9.0 to 10.0 (200 mM borate - LiOH buffer). To investigate $\mathrm{pH}$ stability of $\mathrm{POX}$, the enzyme solution was incubated for $4 \mathrm{~h}$ at different $\mathrm{pHs}$ in the above mentioned buffers, and POX activity then determined using guaiacol as a substrate after addition of $500 \mathrm{mM}$ acetate - LiOH buffer $(\mathrm{pH}$ 5.5 ) to adjust the $\mathrm{pH}$ of the reaction buffer to 5.5. To assess thermal stability, the enzyme solution was incubated for $4 \mathrm{hr}$ at temperatures ranging from $0^{\circ} \mathrm{C}$ to $80^{\circ} \mathrm{C}$ prior to an assay of POX activity at $22^{\circ} \mathrm{C}$ using guaiacol as substrate. The $K_{\mathrm{m}}$ values were determined by Lineweaver-Burk plots at different concentrations of each substrate.

Protein determinations Total soluble protein concentrations were measured using a DC protein assay kit (Bio-Rad, USA) using BSA as a standard protein.

\section{Estimation of molecular weight of F. tataricum POX}

Gel filtration for molecular estimation was carried out using the purified POX. Purified POX was loaded onto a Sephacryl S-200 column $(2.4 \times 66 \mathrm{~cm}$, Amersham Pharmacia Biotech) equilibrated with buffer A. The molecular weight was determined using a standard curve of elution volume vs. $\log \mathrm{MW}$ derived from standard proteins.

\section{Results and Discussion}

Species differences of $P O X \quad$ A comparison of seed POX activities in $F$. tataricum and $F$. esculentum genetic resources/varieties (Table 1) shows that POX activity in $F$. tataricum seeds was an order of magnitude greater than that in F. esculentum seeds. For F. tataricum seeds, POX activity with guaiacol as substrate ranged from 47.5 to 87.3 A490 $\min ^{-1} \mathrm{~g}^{-1}$ (f.w.), but was only 0.3 to $6.1 \mathrm{~A} 490 \mathrm{~min}^{-1} \mathrm{~g}^{-1}$ (f.w.) for F. esculentum seeds. This suggests that seed POX activity in F. tataricum may serve different roles than seed POX in $F$. esculentum. Therefore, we purified the F. tataricum seed POX-containing fraction and characterized it to obtain more information about $F$. tataricum POX.

Purification of POX F. tataricum POX was purified (76.7 fold, final yield $4.77 \%$ ) by concentration, ion-exchange chromatography and gel-filtration (Table 2). The flow through fractions from CM-Sepharose did not contain any detectable POX activity. On the other hand, at the CM-Sepharose step, two peaks indicating POX activity were eluted, one strong and another weak, as in F. esculentum (Suzuki et al., 2006), F. tataricum seed POX activity consisted of at least two isozymes. Although we found two POX peaks, we 
Table 1. Varietal differences of seed POX activity.

\begin{tabular}{lc}
\hline & POX activity ${ }^{1)} \mathrm{mU} / \mathrm{g}$.f.w. flour \\
\hline Tartary buckwheat & \\
Hokkai T8 & $87.3 \pm 8.7$ \\
Nepal 1 & $81.2 \pm 0.9$ \\
Nepal 2 & $61.7 \pm 2.8$ \\
Yugoslavia & $57.9 \pm 0.9$ \\
kuqiao (HUN) & $54.1 \pm 6.9$ \\
putong-Qukiao & $60.9 \pm 1.5$ \\
Ishisoba & $51.4 \pm 12.4$ \\
Amur region & $49.7 \pm 2.4$ \\
Sakhalin Tomari region & $52.3 \pm 4.5$ \\
Latobia & $47.5 \pm 6.3$ \\
\hline common buckwheat & \\
Kitawasesoba & $4.0 \pm 0.1$ \\
Kitayuki & $3.8 \pm 0.2$ \\
Kitanomashu & $3.8 \pm 0.5$ \\
Kanto 1 & $6.1 \pm 0.1$ \\
Shirataki-Nishi & $4.9 \pm 0.4$ \\
Sumchanka & $0.6 \pm 0.2$ \\
cv.monteneuf & $1.0 \pm 0.0$ \\
HC10 & $2.4 \pm 0.2$ \\
Tanno-Hiushinai & $3.7 \pm 0.4$ \\
mh-1 & $0.7 \pm 0.2$ \\
Gan-Chao & $0.3 \pm 0.1$ \\
\hline
\end{tabular}

1) Changes in absorbance at $490 \mathrm{~nm} / \min \times 10^{3}$ enzyme $=1$ unit Guaiacol was used as a substrate

Data are means \pm S.D. $(n=3)$

purified only the one with the strong POX activity, as the other activity peak was too weak to purify. The molecular weight of $F$. tataricum seed POX from the major peak was estimated at $46.8 \pm 1.1 \mathrm{kDa}(\mathrm{n}=3)$, similar to that of POXI (46.1 kD), a POX isozyme showing trace activity in F. esculentum seeds (Suzuki et al., 2006). These molecular weights were also similar to those reported for POX in scented geranium (Pelargonium graveolens; Seok et al., 2001) and oil palm (Elaies guineensis; Sakharov et al., 2000). On the other hand, the molecular weight of POXII, the major POX isozyme in F. esculentum seed, is $58.1 \mathrm{kDa}$. These data indicate that the molecular weight of the major active POX fraction in F. esculentum and F. tataricum are quite different, suggesting that their characteristics may differ significantly.

Kinetic constants of POX The determination of $F$. tataricum POX $K_{\mathrm{m}}$ values for various substrates (data not shown), showed its $K_{\mathrm{m}}$ for guaiacol $(0.958 \mathrm{mM})$ to be far lower than that of isoperoxidase PC3 from P. graveolens (7.3 mM; Seok et al., 2001) or that of a neutral peroxidase isozyme from Brassica napus L. (3.7 mM; Duarte-Vazquez et al., 2001). F. tataricum POX's $K_{\mathrm{m}}$ value for ABTS (1.86 $\mathrm{mM}$ ) was higher than that of a neutral peroxidase isozyme from B. napus (0.7 mM; Duarte-Vazquez et al., 2001), while for $o$-dianisidine $(0.316 \mathrm{mM})$ it was similar to the $K_{\mathrm{m}}$ of isoperoxidase PC3 from $P$. graveolens $(0.31 \mathrm{mM}$; Seok et al., 2001). Among the substrates tested, F. tataricum POX showed its lowest $K_{\mathrm{m}}$ value for quercetin and $o$-dianisidine. Quercetin is one of the major phenolic compounds in F. tataricum seeds. Given that several reports have shown that POX, along with phenolic compounds such as quercetin, play an important role in enzymatic browning (Kondo et al., 1982; Francisco et al., 2001), F. tataricum POX may be implicated in color change of buckwheat noodles. While for every substrate tested $F$. tataricum POX's $K_{\mathrm{m}}$ values were higher than corresponding ones for $F$. esculentum POX, the greater quantity of POX activity in F. tataricum may balance the lesser specificity of its POX.

Optimal pH, pH stability, optimum temperature and thermal stability of POX The optimum $\mathrm{pH}$ of $F$. tataricum POX was investigated using quercetin, ABTS and guaiacol as substrates (Table 3). For quercetin and guaiacol, the optimum $\mathrm{pH}$ was 6.0, though high activity was observed at $\mathrm{pH} 4.0,5.0$ and 6.0. Although F. tataricum POX was active on guaiacol over a $\mathrm{pH}$ range of 2.0 to 10.0 , for quercetin its activity did not extend above $\mathrm{pH}$ 7.0.

The optimum $\mathrm{pH}$ for ABTS was $\mathrm{pH} 2.0$, and activity gradually decreased with an increase of $\mathrm{pH}$. Comparatively, the $\mathrm{pH}$ optima for F. esculentum POX activity are $\mathrm{pH} 8.0$ for POXI, and $\mathrm{pH} 4.5$ for POXII with quercetin as substrate. In addition, the $\mathrm{pH}$ optima for $F$. esculentum POX activity are pH 3.0 for POXII, and undetectable for POXI with ABTS as substrate (Suzuki et al., 2006). This indicates that $F$. tataricum seed POX had a similar pH optima as F. esculentum seed POXII, which is a major POX isozyme in this species.

Table 2. Purification of POX from Tartary buckwheat seed.

\begin{tabular}{cccccc}
\hline Purification step & $\begin{array}{c}\text { Total pro tein } \\
(\mathrm{mg})\end{array}$ & Total activity units ${ }^{1)}$ & $\begin{array}{c}\text { Specific activity } \\
\text { units / mg protein }\end{array}$ & $\begin{array}{c}\text { Yield } \\
(\%)\end{array}$ & Fold \\
\hline crude extract & 643 & 376 & 0.585 & 100 & 1.00 \\
concentration & 161 & 546 & 3.39 & 145 & 5.79 \\
CM-Sepharose & 3.85 & 41.3 & 10.7 & 11.0 & 18.3 \\
Sephacryl S-200 & 0.400 & 17.9 & 44.8 & 4.77 & 76.7 \\
\hline
\end{tabular}

${ }^{1)}$ Changes in absorbance at $490 \mathrm{~nm} / \min \times 10^{3}$ enzyme $=1$ unit

POX activity was measured using guaiacol as a substrate. 
Table 3. Optimum $\mathrm{pH}$ and $\mathrm{pH}$ stability of POX.

\begin{tabular}{|c|c|c|c|c|}
\hline \multirow{2}{*}{$\mathrm{pH}$} & \multicolumn{3}{|c|}{ optimum $\mathrm{pH}^{1)}$} & \multirow{2}{*}{$\frac{\mathrm{pH}_{\text {stability }}{ }^{1)}}{\text { guaiacol }}$} \\
\hline & quercetin & guaiacol & ABTS & \\
\hline 2.0 & $33 \pm 1.7 \mathrm{a}$ & $9 \pm 3.3 \mathrm{a}$ & $100 \pm 5.7 \mathrm{a}$ & N.D. \\
\hline 3.0 & $68 \pm 5.6 b$ & $21 \pm 7.9 \mathrm{ab}$ & $67 \pm 1.1 \mathrm{~b}$ & $1 \pm 0.0 \mathrm{a}$ \\
\hline 4.0 & $89 \pm 4.6 \mathrm{c}$ & $68 \pm 14.6 \mathrm{c}$ & $84 \pm 3.3 \mathrm{c}$ & $38 \pm 1.2 \mathrm{~b}$ \\
\hline 5.0 & $100 \pm 8.2 \mathrm{c}$ & $93 \pm 12.0 \mathrm{~d}$ & $26 \pm 2.7 \mathrm{~d}$ & $59 \pm 3.3 \mathrm{c}$ \\
\hline 6.0 & $4 \pm 2.7 \mathrm{~d}$ & $100 \pm 19.3 \mathrm{~d}$ & $6 \pm 1.4 \mathrm{e}$ & $100 \pm 11.5 \mathrm{~d}$ \\
\hline 7.0 & N.D. & $55 \pm 8.3 \mathrm{c}$ & N.D. & $34 \pm 1.7$ be \\
\hline 8.0 & N.D. & $43 \pm 8.4 b c$ & N.D. & $30 \pm 1.6$ be \\
\hline 9.0 & N.D. & $15 \pm 2.2 \mathrm{ab}$ & N.D. & $23 \pm 1.0 \mathrm{e}$ \\
\hline 10.0 & N.D. & $21 \pm 3.9 \mathrm{ab}$ & N.D. & $6 \pm 0.7 \mathrm{a}$ \\
\hline
\end{tabular}

${ }^{1)}$ Guaiacol and quercetin; $\mathrm{pH} 6.0=100$, ABTS; pH $2.0=100$

Data are means \pm S.D. $(n=3)$, N.D.; not detectable

Different alphabets within column indicate significant difference between means using Ryan's test at $\mathrm{p}=0.05$

The $\mathrm{pH}$ stability of $F$. tataricum POX was greatest at $\mathrm{pH}$ 6.0 , and diminished at increasing and decreasing $\mathrm{pH}$ values. This indicates that to purify F. tataricum seed POX, pH 5.5 is appropriate in terms of enzyme stability. With guaiacol as substrate, F. tataricum seed POX showed activity between $0^{\circ} \mathrm{C}$ and $50^{\circ} \mathrm{C}$, but none above $60^{\circ} \mathrm{C}$ (Table 4). While its optimal temperature was $20^{\circ} \mathrm{C}$, its activity at $0^{\circ} \mathrm{C}$ and $10^{\circ} \mathrm{C}$ was roughly halved. These characteristics were similar to those of POXI in F. esculentum seed. However F. tataricum POX was more stable at high temperatures than $F$. esculentum POXI or POXII. F. tataricum POX was stable from $0^{\circ} \mathrm{C}$ to $40^{\circ} \mathrm{C}$, and retained activity when kept at $60^{\circ} \mathrm{C}$ for $4 \mathrm{~h}$ (Table 4). On the other hand, F. esculentum POXI and POXII were unstable above $40^{\circ} \mathrm{C}$ and quickly lost activity at $60^{\circ} \mathrm{C}$ (Suzuki et al., 2006).

F. tataricum seed POX clearly has unique characteristics compared to F. esculentum POXs, as well as those of other plant species. In F. esculentum seeds, most of the quercetin,

Table 4. Optimum temperature and thermal stability of POX.

\begin{tabular}{ccc}
\hline${ }^{\circ} \mathrm{C}$ & optimum temperature $^{1)}$ & thermal stability $^{2)}$ \\
\hline 0 & $40 \pm 1.5 \mathrm{ab}$ & $93 \pm 1.1 \mathrm{a}$ \\
10 & $57 \pm 2.3 \mathrm{~b}$ & $100 \pm 2.9 \mathrm{a}$ \\
20 & $100 \pm 9.7 \mathrm{c}$ & $98 \pm 3.6 \mathrm{a}$ \\
30 & $48 \pm 8.1 \mathrm{ab}$ & $95 \pm 4.2 \mathrm{a}$ \\
40 & $32 \pm 2.5 \mathrm{a}$ & $89 \pm 6.5 \mathrm{a}$ \\
50 & $11 \pm 0.7 \mathrm{~d}$ & $75 \pm 3.8 \mathrm{~b}$ \\
60 & N.D. & $46 \pm 4.3 \mathrm{c}$ \\
70 & N.D. & N.D. \\
80 & N.D. & N.D. \\
\hline
\end{tabular}

1) $20^{\circ} \mathrm{C}=100,{ }^{2)} 10^{\circ} \mathrm{C}=100$

Data are means \pm S.D. $(n=3)$, N.D.; not detectable

Guaiacol is used as a substrate

Different alphabets within column indicate significant

difference between means using Ryan's test at $p=0.05$ rutin (quercetin 3-rutinoside) and isoquercitrin (quercetin 3 -glucoside) are localized in the embryo (Suzuki et al., 2002). The same is the case in F. tataricum seeds, where the majority of POX activity is also localized in the embryo. Quercetin, generated from rutin by hydrolysis (Suzuki et al., 2002; Yasuda, et al., 1994), serves as a substrate for peroxidase-dependent oxidation of quercetin to the anti-fungal agent 3,4-dihydroxybenzoic acid (Takahama et al., 2000). Based on our results, we propose that when quercetin is used as a substrate, POX activity in F. tataricum seeds or flour may have a role in the generation of an anti-fungal agent along with antioxidant activity. To clarify the role of POX in F. tataricum seeds, further studies should investigate if there exists a clear relationship between the quality of $F$. tataricum products and the seeds' POX activity.

Acknowledgment We thank Mr. K. Abe, T. Takakura, and T. Hirao for their assistance in the field. We also thank Ms. K. Fujii and Ms. M. Hayashida for their technical assistance in the laboratory experiments. This study was supported by the NIAS Genebank Project of the National Institute of Agrobiological Sciences.

\section{References}

Anli, D., and Tilak, R.M. (2004). Off-flavour development in soybeans: comparative role of some antioxidants and related enzymes. J. Sci. Food Agric., 84, 547-550.

Ahmed, N., Chaplin, M., Trevan, M., Dey, P.M. and Brownleader, M.D. (1995). Purification and partial characterization of 'extensin peroxidase'. Biochem. Soc. Trans., 23, 154.

Ashie, N.A., Simpson, B.K. and Smith, J.P. (1996). Mechanisms for controlling enzymatic reactions in foods. Crit. Rev. Food Sci. Nutr., 36, 1-30.

Blee, K.A., Choi, J.W., O'Connell, A.P., Schuch, W., Lewis, N.G. and Bolwell, G.P. (2003). A lignin-specific peroxidase in tobacco 
whose antisense suppression leads to vascular tissue modification. Phytochem., 64, 163-176.

Bradley, D.J., Kjellbom, P. and Lamb, C.J. (1992). Elicitor- and wound-induced oxidative cross-linking of a proline-rich plant cell wall protein: a novel, rapid defense response. Cell, 70, 21-30.

Duarte-Vazquez, M.A., Garacia-Almendarez, B.E., Regalado, C. and Whitaker, J.R. (2001). Purification and properties of a neutral peroxidase isozyme from turnip (Brassica napus L. var. purple Top White Globe) root. J. Agric. Food Chem., 49, 4450-4456.

Francisco, A.T. and Juan, C.E. (2001). Phenolic compounds and related enzymes as determinants of quality in fruits and vegetables. J. Sci. Food Agric., 81, 853-876.

Ibaraki, T., Hirano, T., Yamashita, N. and Baba, N. (1988). Studies on peroxidase activity of butterbur. Bull. Fukuoka. Agric. Res. Cent., B-8, 67-72 (in Japanese).

Ibaraki, T. and Hirano, T. (1989). Control of peroxidase and polyphenoloxidase activities, and the preserve of chlorophylls in processing of waterboiled butterbur. Bull. Fukuoka. Agric. Res. Cent., B-9, 85-90 (in Japanese).

Kolattukudy, P.E., Mohan, R., Bajar, A.A. and Scherf, B.A. (1992). Plant peroxidase gene expression and function. Biochem. Soc. Trans., 20, 333-337.

Kondo, K., Kurogouti, T. and Matubashi, T. (1982). (English title not available). Report in Research Institute of Food Technology in Nagano Prefecture, 10, 150 (in Japanese).

Matoba, T., Hidaka, H., Kitamura, K., Kaizuma, N. and Kito, M. (1975). Contribution of hydroperoxide lyase activity to n-hexanal formation in soybean. J. Agric. Food Chem., 23, 136-141.

Matoba, T., Hidaka, H., Narita, H., Kitamura, K., Kaizuma, N., and Kito, M. (1985). Lipoxygenase-2 isozymes is responsible for generation of n-hexanal in soybean homogenates. J. Agric. Food Chem., 33, 852-855.

Muramatsu, N., Ohinata, H., Obara, T. and Matsubashi, T. (1986). (English title not available) Food Packaging, 30, 94 (in Japanese).

Ohinata, H., Karasawa, H., Muramatsu, N. and Ohike, T. (1997). Properties of buckwheat lipase and depression of free fatty acid accumulation during storage. Nippon Shokuhin Kagaku Kogaku
Kaishi, 44(8), 590-593 (in Japanese).

Sakharov, I.Y., Castillo, J., Areza, J.C. and Calaev, I. (2000). Purification and stability of peroxidase of African oil palm Elaies guineensis. Bioseparation, 9, 152-132.

Seok, H.L., Eun, S.K. and Mi, Y.L. (2001). Purification and characterization of a cationic isoperoxidase from scented-geranium. Phytochem., 58, 859-864.

Suzuki, T., Honda, Y., Funatsuki, W. and Nakatsuka, K. (2002). Purification and characterization of flavonol 3-glucosidase, and its activity during ripening in tartary buckwheat seeds. Plant Sci., 163, 417-423.

Suzuki, T., Honda, Y., Funatsuki, W. and Nakatsuka, K. (2004). Ingel detection and study of the role of flavonol 3-glucosidase in the bitter taste generation in tartary buckwheat. J. Sci. Food Agric., 84, 1691-1694.

Suzuki, T., Honda, Y. and Mukasa, Y. (2004). Purification and characterization of lipase in buckwheat seed. J. Agric. Food Chem., 52, 7407-7411.

Suzuki, T., Honda, Y., Mukasa, Y., and Kim, S-J. (2005). Effects of lipase, lipoxygenase, peroxidase, and rutin on quality deteriorations in buckwheat flour. J. Agric. Food Chem., 53, 8400-8405.

Suzuki, T., Honda, Y., Mukasa, Y. and Kim, S-J. (2006). Characterization of peroxidase in buckwheat seed. Phytochem., 67, 219224.

Takahama, U. and Hirota, S. (2000). Deglucosidase of quercetin glucosides to the aglycone and formation of antifungal agents by peroxidase-dependent oxidation of quercetin on browning of onion scales. Plant Cell Physiol., 41, 1021-1029.

Tohyama, R., Sekizawa, N., Murai, K. and Ishiya, T. (1982). Quality change in packaged buckwheat during storage. Nippon Shokuhin Kagaku Kogaku Kaishi, 29, 501 (in Japanese).

Van Huystee, R.B., and Cairns, W.L. (1982). Progress and prospects in the use of peroxidase to study cell development. Phytochem., 21, 1843-1847.

Yasuda, T. and Nakagawa, H. (1994). Purification and characterization of rutin-degrading enzymes in tartary buckwheat seeds. Phytochem., 37, 133-136. 